\title{
Multiple spinal extradural arachnoid cysts occurring in a child
}

\author{
Case report
}

\author{
Wihasto Suryaningtyas, M.D., And Muhammad Arifin, M.D., Ph.D. \\ Department of Neurosurgery, Airlangga University School of Medicine, Soetomo General Hospital, \\ Surabaya, Indonesia
}

\begin{abstract}
$\checkmark$ Symptomatic multiple extradural arachnoid cysts of the spine are extremely uncommon in children and have only rarely been reported. The authors report a case of multiple extradural spinal arachnoid cysts in a 14-year-old child who presented with signs of spinal cord compression. The disease affected the thoracic spine and extended from T-5 to T-10 with an underlying defect in the dura of the spinal canal that was predisposed to the formation of cysts. The authors describe the imaging examination, surgical planning, and surgical technique, and they review the literature. They also discuss the possible mechanisms of cyst formation.
\end{abstract}

KEY WORDS • extradural cyst • spinal arachnoid cyst • pediatric neurosurgery

$\mathrm{S}$ PINAL extradural cysts are rare $e^{1,2,8,12,14}$ and consist of two known types. One type occurs in adolescents in the dorsal spine and is associated with evidence of kyphosis juvenilis, and the other occurs in adults in the dorsolumbar spine without kyphosis. Although spinal arachnoid cysts are not uncommon findings in adults, they are much less frequently reported in children. Extradural arachnoid cysts or diverticula are less common than intradural cysts. ${ }^{8}$ Solitary extradural arachnoid cysts have been reported in several studies, but multiple extradural arachnoid cysts are very rarely reported. There are only two reports in which multiple lesions are described; ${ }^{3,8}$ in only one of these is a "true" case of multiple lesions reported. ${ }^{8}$ We report on a 14-year-old boy who presented with symptomatic multiple extradural cysts. Each cyst was associated with a dural defect, suggesting an underlying weakness of the dura mater of the spinal canal. Successful surgical management required preoperative imaging recognition of the multiple dural defects.

\section{Case Report}

History and Examination. This 14-year-old boy presented with a 4-month history of progressive bilateral leg weakness that was causing gait clumsiness. He complained of an un-

Abbreviations used in this paper: $\mathrm{CSF}=$ cerebrospinal fluid; $\mathrm{MR}=$ magnetic resonance. usual pain sensation in his knees and legs bilaterally when he walked and experienced frequent stumbling and falls. One year before presentation, he had suffered intermittent weakness in both legs that spontaneously resolved. He had no other history of illness or trauma, and there was no family history of spinal disease.

On examination we found no spinal deformity, gibus, cutaneous stigmata of neurological disease, or dysmorphic features. The patient had a clumsy gait and bilateral leg weakness that became more pronounced when he walked on his toes or tiptoes. Hypesthesia was noted to extend from the sensory level of T-7 down both legs. Abdominal reflexes were absent, bilateral plantar extension responses were present, and both Achilles tendons were hyperreflexic. The bladder was not palpable, and perineal sensation and anal tone were normal.

Midsagittal and axial $\mathrm{T}_{1}$ - and $\mathrm{T}_{2}$-weighted thoracic spine MR images demonstrated extensive cystic lesions causing spinal cord compression. The cord was flattened and displaced anteriorly extending from T-5 to T-10 (Fig. 1A and B). A myelogram revealed a complete block at the T5-10 levels and showed communication with the spinal subarachnoid space (Fig. 1C). Axial $\mathrm{T}_{2}$-weighted images obtained at T-5 and T-6 clearly showed that the cystic lesions were extradural in location (Fig. 2). The cysts contained fluid that had the same signal characteristics as CSF and appeared hyperintense on $\mathrm{T}_{2}$-weighted images. They compressed the thecal sac and spinal cord ventrally. 


\section{Spinal extradural arachnoid cysts}
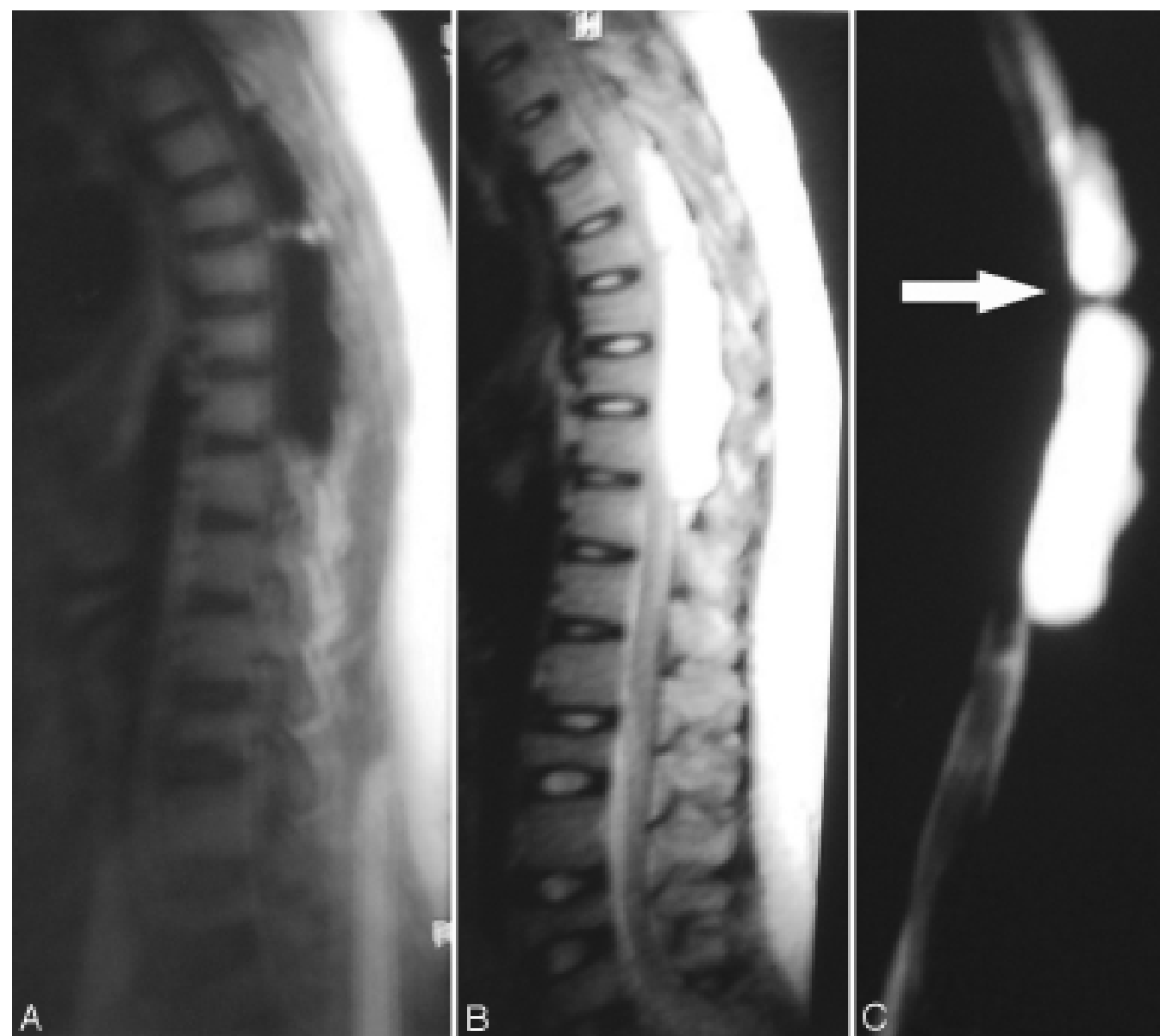

FIG. 1. A and B: Midsagittal $\mathrm{T}_{1}$-weighted $(\mathrm{A})$ and $\mathrm{T}_{2}$-weighted (B) thoracic spine $\mathrm{MR}$ images demonstrating extensive cystic lesions causing spinal cord compression. The spinal cord is pushed ventrally in the spinal canal. C: Magnetic resonance myelogram showing a cystic lesion with septae that separate the cysts (arrow).

Operation. A T5-11 laminotomy was performed. The spinal canal was found to be occupied by a large translucent cyst, and its wall was likely formed by the thickened arachnoid membrane (Fig. 3). Two separate cysts were noted. One cyst extended from the lower border of T-4 to T-5, and the other extended from the lower border of T-5 to T-11.
The cysts were easily separated from the dura, which had been pushed forward by the cyst and appeared to arise from a small neck protruding through a defect in the dura of the left T-5 and right T- 6 nerve root. Both of the cyst necks were excised, and the dural defect was sutured in a watertight fashion. The spinal cord was completely decompressed.

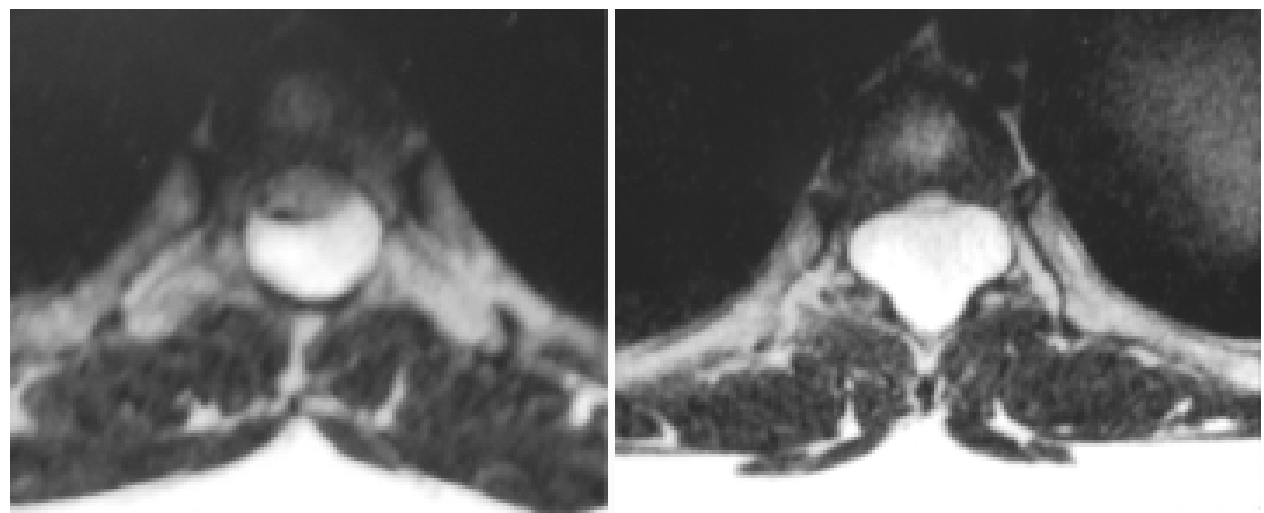

FIG. 2. Axial $\mathrm{T}_{2}$-weighted MR images obtained at T-5 (left) and T-6 (right), clearly showing that the cystic lesions are extradural in location. 

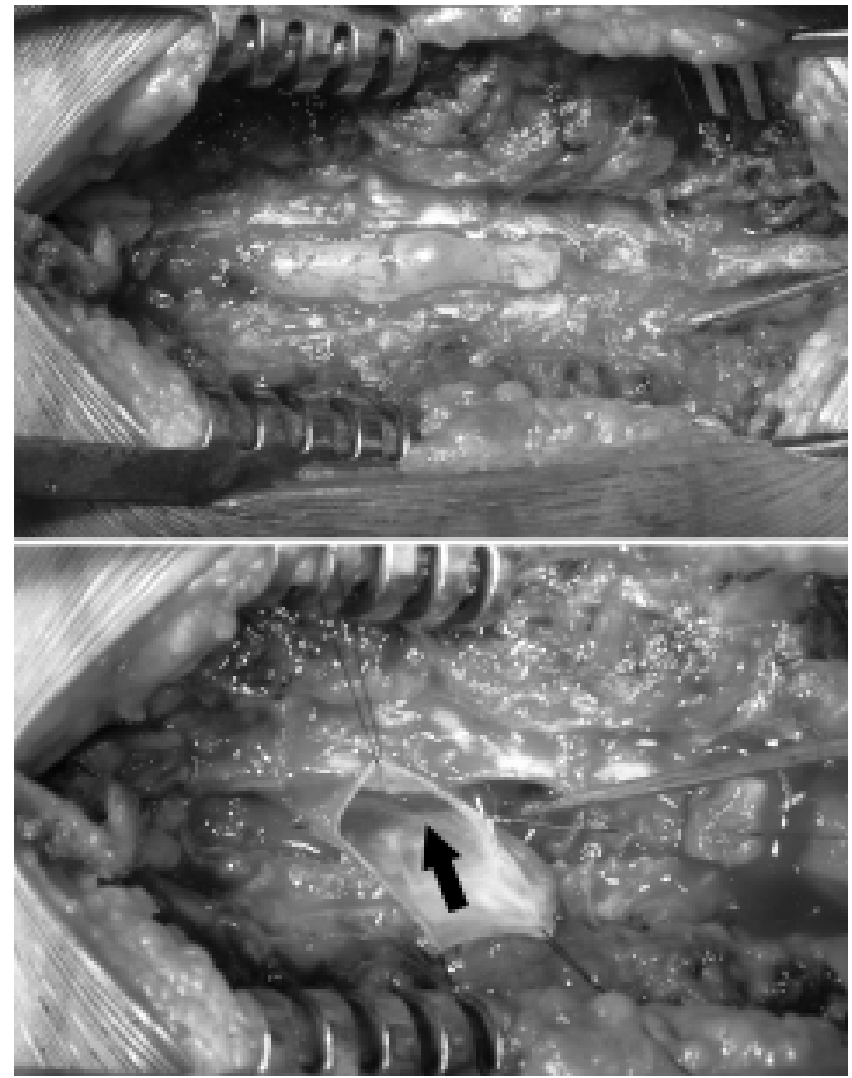

FIG. 3. Intraoperative photographs obtained following T5-11 laminotomy. Upper: The translucent cysts within the wall were likely formed by thickened arachnoid membrane cyst. Lower: After opening the cyst wall, a dural defect (arrow) can be seen at the level of the right side of T-6.

Pathological Examination. Pathological examination of the cyst wall revealed a thin arachnoid layer lined by discrete nests of meningothelial cells. The lesion was diagnosed as an arachnoid cyst.

Postoperative Course. The patient's signs and symptoms improved, and by the time of hospital discharge, the strength in his lower extremities was normal. His leg pain subsided, he had full power in his lower limbs with brisk jerks and downgoing plantar responses, and his bladder function was normal. The patient has been wearing a thoracic brace to prevent progressive kyphosis after the extensive laminotomy procedure.

\section{Discussion}

Spinal extradural cysts are herniations of the arachnoid mater through an aperture in the dura mater, producing a cyst containing CSF in communication with the spinal canal. ${ }^{1,2}$ Spinal arachnoid cysts are relatively uncommon lesions, ${ }^{2,8,12}$ and symptomatic spinal arachnoid cysts in children are rare. ${ }^{8,12}$ Although classification of these cysts has proved to be somewhat complicated, Nabors et al. ${ }^{9}$ have simplified their classification into three major categories: extradural cysts without nerve root fibers (Type I); extradural cysts with nerve root fibers (Type II); and intradural cysts (Type III). Spinal extradural meningeal cysts are most often located in the mid- to lower thoracic area, are found predominantly in male patients, and tend to be symptomatic during the second decade of the patient's life. . $^{814}$

The causes and natural history of pediatric arachnoid cysts are unclear. They are known to be associated with trauma, surgery, arachnoiditis, and neural tube defects. ${ }^{3-5,8}$, ${ }^{10,13}$ Familial cysts have been reported, and there is an association with lymphedema and distichia. In many cases there is no underlying cause, and the lesions are believed to be congenital. Some authors believe that idiopathic or congenital arachnoid cysts should be differentiated from those that occur secondary to trauma, surgery, or arachnoiditis because they are characterized by distinctive imaging appearances and most often present with neurological symptoms and signs. ${ }^{1,2,8}$ Our patient had no history of trauma, surgery, or evidence of arachnoiditis on imaging studies. Although the bone changes were not observed on images and at the time of surgery, the history of gait clumsiness for a long period suggested that the patient harbored a long-standing congenital lesion. Another possible origin of the lesion is that it resulted from an incompetent dura. Two lesions at approximately the same level-with no lesion above or below-suggests that the problem resulted from a rupture of the dura mater while the arachnoid remained intact.

The hypothesis currently accepted to explain the progressive enlargement of these arachnoid cysts involves two principal theories. ${ }^{12}$ Active (noncommunicating arachnoid cyst) and passive (ball-valve hypothesis) fluid-transport mechanisms have been hypothesized to explain enlargement of extradural meningeal cysts. ${ }^{12,14}$ According to the first theory an arachnoid cyst may enlarge even when it does not communicate with the subarachnoid space (noncommunicating arachnoid cyst) because of fluid production by the cells forming its wall. The second theory (the ball-valve hypothesis) postulates the existence of an anatomical communication functioning as a one-way valve between the subarachnoid space and the cyst, which allows the CSF to enter the cystic cavity (communicating cyst). ${ }^{12}$ Failure of the histopathological examination to reveal an inner single-cell lining of extradural meningeal cysts or cells with a secretory capability makes most investigators now prefer the passive fluid-transport theory to explain the cause of cyst expansion via pulsatile CSF dynamics and an osmotic gradient with or without valve-like mechanisms. ${ }^{6,7,11}$ In the early stages, pulsatile CSF dynamics may act as a factor to enlarge the cyst; ${ }^{7}$ an osmotic gradient can then facilitate further expansion. ${ }^{6}$

In our case, the cyst deflated immediately after intraoperative needle aspiration but re-expanded within a few minutes. Direct inspection of the inner surface of the cyst confirmed that the influx of CSF through the dural defect followed forced inflation of the lungs. Although an osmotic pressure gradient may be partly responsible for cyst enlargement, intraoperative findings strongly supported a valve-like mechanism as reported by Rohrer et al. ${ }^{11}$

Magnetic resonance imaging is a useful tool for diagnosing intraspinal meningeal cysts. In our case, this modality provided clear anatomical information and demonstration of pathological changes. The hyperintense lesion located in the spinal cord in our case was caused by long-standing spinal cord compression by the cyst. Although the prognosis of extradural meningeal cysts is favorable, only one third of patients attain remission with complete recovery.

There are several reports in the literature of children pre- 
senting with spinal extradural cystic lesions; however, there are only two reports of a child presenting with multiple extradural spinal arachnoid cysts. Duncan and Hoare ${ }^{3}$ reported on one child with a myelomeningocele composed of multiple intradural spinal arachnoid cysts found in the thoracic region only; these cysts may represent a single cyst that was divided by inflammatory adhesions. The other case by Myles et al. ${ }^{8}$ is similar to ours in that each cyst had a separate neck extending through a dural opening that allowed the cyst (or more correctly, diverticulum) to communicate with the spinal subarachnoid space.

Small extramedullary cysts may be treated conservatively, but in cases of intramedullary cysts, the neurological deficits may be more pronounced and manifest earlier. Surgical treatment is necessary if progressive neurological dysfunction appears in the course of spinal cord compression. There is a general agreement that the successful treatment of a spinal arachnoid cyst requires total excision whenever possible. However, in cases in which the cyst cannot be resected completely because of dense fibrous adhesion to the spinal cord or nerve roots and/or it is located anterior to the spinal cord, partial resection and fenestration should be performed as widely as possible. ${ }^{5,12}$

Because the remaining cystic wall cannot cause recurrence, total resection is unnecessary if the posterior wall of the theca has been explored and the dural rent has been obstructed. ${ }^{14}$

\section{References}

1. Dickson RA, Arabi K, Goodfellow J: Congenital spinal extradural cyst (lateral meningocele) stimulating acute transverse myelitis. Report of a case. J Bone Joint Surg Br 60: 412-415, 1978

2. Du Toit JG, Fainsinger MH: Spinal extradural cysts. J Bone Joint Surg Br 30:613-618, 1948

3. Duncan AW, Hoare RD: Spinal arachnoid cysts in children. Radiology 126:423-429, 1978
4. Hoffman EP, Garner JT, Johnson D, Shelden CH: Traumatic arachnoidal diverticulum associated with paraplegia. Case report. J Neurosurg 38:81-85, 1973

5. Kotil K, Akçetin MA, Güzel N, Bilge T: Spinal intradural arachnoid cyst with spinal dysraphism. J Pediatr Neurol 2:235-239, 2004

6. Lake PA, Minckler J, Scanlan RL: Spinal epidural cyst: theories of pathogenesis. Case report. J Neurosurg 40:774-778, 1974

7. McCrum C, Williams B: Spinal extradural arachnoid pouches. Report of two cases. J Neurosurg 57:849-852, 1982

8. Myles LM, Gupta N, Armstrong D, Rutka JT: Multiple extradural arachnoid cysts as a cause of spinal cord compression in a child. Case report. J Neurosurg 91 (1 Suppl):116-120, 1999

9. Nabors MW, Pait TG, Byrd EB, Karim NO, Davis DO, Kobrine AI, et al: Updated assessment and current classification of spinal meningeal cysts. J Neurosurg 68:366-377, 1988

10. Rabb CH, McComb JG, Raffel C, Kennedy JG: Spinal arachnoid cysts in the pediatric age group: an association with neural tube defects. J Neurosurg 77:369-372, 1992

11. Rohrer DC, Burchiel KJ, Gruber DP: Intraspinal extradural meningeal cyst demonstrating ball-valve mechanism of formation. Case report. J Neurosurg 78:122-125, 1993

12. Sharma A, Sayal P, Badhe P, Pandey A, Diyora B, Ingale H: Spinal intramedullary arachnoid cyst. Indian J Pediatr 71: e65-e67, 2004

13. Taguchi Y, Suzuki R, Okada M, Sekino H: Spinal arachnoid cyst developing after surgical treatment of a ruptured vertebral artery aneurysm: a possible complication of topical use of fibrin glue. Case report. J Neurosurg 84:526-529, 1996

14. Uemura K, Yoshizawa T, Matsumura A, Asakawa H, Nakamagoe K, Nose T: Spinal extradural meningeal cyst. Case report. J Neurosurg 85:354-356, 1996

Manuscript submitted July 11, 2006.

Accepted October 17, 2006.

Address reprint requests to: Wihasto Suryaningtyas, M.D., Department of Neurosurgery, Airlangga University School of Medicine, Soetomo General Hospital, Karangmenjangan 12, Surabaya, East Java, Indonesia 60285. email: w_hasto@yahoo.co.uk. 